\title{
Bacillus cereus as a biotemplating agent for the synthesis of zinc oxide with raspberry- and plate-like structures
}

\begin{abstract}
Currently the development of green chemistry approach with the use of biomaterial-based activities of microbial cells in the synthesis of various nanostructures has attracted a great attention. In this study, we report on the use of bacterium, Bacillus cereus as a biotemplating agent for the formation of zinc oxide nanoparticles with raspberry- and plate-like structures through a simple thermal decomposition of zinc acetate by maintaining the original $\mathrm{pH}$ of the reaction mixtures. Possible mechanism on the formation of the nanostructures is proposed based on the surface chemistry and biochemistry processes involved organic-inorganic interactions between zinc oxide and the microbial cells.
\end{abstract}

Keyword: Hydrothermal; Complexation; Biotemplating agent; Zinc oxide; Nanobiotechnology 